\title{
The Effect of Using Video on Developing Physical Fitness of Physical Education Students at the Hashemite University
}

\author{
Mahmoud. A. Al-Haliq ${ }^{1}$, Mo'een. A. Oudat $^{1} \&$ Mohammad. Abu Al-Taieb ${ }^{2}$ \\ ${ }^{1}$ Faculty of Physical Education and Sport Sciences, The Hashemite University, Jordan \\ ${ }^{2}$ Faculty of Physical Education, University of Jordan, Jordan \\ Correspondence: Mo'een. A. Oudat, Faculty of Physical Education and Sport Sciences, The Hashemite \\ University, Jordan. Tel: 962-77-778-3755. E-mail: dr.moeenodat@gmail.com
}

\author{
Received: July 24, 2013 Accepted: October 31, 2013 Online Published: December 31, 2013 \\ doi:10.5539/ass.v10n1p21 \\ URL: http://dx.doi.org/10.5539/ass.v10n1p21
}

\begin{abstract}
The purpose of this study was to determine the effect of video on developing physical fitness to physical education students at the Hashemite University. The study sample consisted of (20) Physical education students They were divided into two groups, the control group (10) students went through traditional physical practice method, and the experimental group (10) students went through physical practice using video, Pre and post-tests were carried out to measure student's development in physical fitness (Vertical jump from stability, Throwing and receiving the ball, Trunk bending forward from standing, Zigzag running, Throwing a ball to the farthest distance and $25 \mathrm{~m}$ running). Statistical analysis included t-Test for mean at pre and post test for the two groups, and t-Test for mean at post test in the two groups. The results showed significant differences $(p<0.05)$ in post test between the two groups in favor of the experimental group, it is concluded that using video improved physical fitness level more than the traditional method. The researchers recommended using video to developing physical fitness.
\end{abstract}

Keywords: teaching styles, video, traditional method, physical fitness

\section{Introduction}

Educational institutions seek to achieve the objectives of the educational process with a high efficiency, accuracy for the individual learner, through new teaching styles that help the student to make a positive participation in the educational process. This innovation and development in the teaching styles aims to get the learner approach the high efficiency and achieve the anticipated goals. (Mohammed, 2006) Learning is influenced, to a far extent, by the teaching styles used by the teacher. Therefore, teaching based on experimentation and application with its effects are transferred easier and faster than learning indoctrinated into the learner. New methods in teaching manners emerged which help to shift the activity center in the learning process from the teacher and the subject matter to the learner. (AL-Labani, 1991). It is necessary to use more than one way to transfer the information to the students through diversification and development of physical education teaching styles, in order to address the individual differences by better methods. In fact, there is no single ideal method to teach physical education, and the selection of the method is primarily based on the educational status of each educational setting (Moston, 1981).

Teaching makes acquisition of knowledge and skills possible through systematic interaction between teachers and learners. It happens every day and involves teacher, learner, and methodology and materials interaction. Part of these materials is known as instructional resources. The uses of instructional materials in teaching process provide the basis for improved teaching and learning of a subject. They are designed, produced and use to achieve specific instructional goal. The use of audio and visual media contributes to saving time, increasing knowledge and understanding, and interest of students. They help students to recognize problems, provide solutions, and make the instructions more effective (Ayinde, 1999). Alaku (1998) stated that teachers' effectiveness depends on the use of appropriate instructional strategies and audio-visual aids. Appropriate instructional strategies portray good teaching techniques and successful learning. They assist students to enjoy and understand lessons easily especially when they are attached with appropriate methodology. Video is a very important example of instructional materials. 
Physical education teacher plays a major role in diversifying the introduction of information to the students, providing them with skills and abilities, and availing a degree of social discipline during the lesson, to a degree allowing a smooth running of the educational process without any interruption. Furthermore, the use of the suitable teaching styles and utilization of the environmental resources in the teaching process will reflect the teacher's mastership in showing his/her material clearly.

With the development of the educational field, many ways and methods appeared to deal with the students, to rise up the students' abilities, physical, psychological and cognitive, abilities through applying the well-established basic principles of teaching, for which pre-planning and deep thinking are the most important features to define what and how the teacher will teach (Oudat, 2006). The use of the modern teaching styles positively contributes in realization of the teaching fruits, and increases the success and achievement of the students in a desired manner. It further contributes in raising the level of physical qualities and skills of the students. Moreover, it helps in thinking and experimentation to find out new teaching styles that contribute in overcoming the difficulties and impediments that face the physical education teacher (AL-Sayyad, 2005).

Video has a vital role in teaching and learning and teachers benefited from it to motivate students and increase their interest through the senses of sight and hearing. In spite of the fact that there are varieties of physical education teaching styles, yet the traditional way in teaching still exists. Meanwhile, the modern educational trends are calling for the necessity of the development and modernity of the teaching styles. They also call for giving interest to the learner, to become an active and positive participant in the learning process, through implementing and evaluating decision-making processes, so that every student will depend on himself/herself in accepting the responsibility, and becoming positive, as well seeking to obtain the information. Using the Video, each learner depends on himself in learning and establishing the motor skills, as the motor assignments are provided to him through a paper that includes the teaching steps, with different and graded difficulty levels, which he/she has to carry out to achieve the desired goals (Oudat, 2012).

Through the experience and work of the researchers in teaching field, they noticed the decline of the performance level of many students in physical education lessons, as well as their poor physical fitness in performing the basic skills in the various activities. They further noticed the students' tendency to have excuses not to participate in physical education lessons. This promoted the researchers to use modern physical education teaching styles in order to revitalize the students and raise their physical abilities level, as well as raising the skill level in the different skills already taught in physical education lessons. The researchers attribute this weakness to the possibility of irrelevance of the time allocated to teach this subject, increase of the numbers of students in one lesson as well as the use of the traditional methods in teaching physical education. Therefore, the researchers thought of applying some modern methods that may help in better teaching styles. This, by turn, will help students improve their performance skill. Thus, the researchers found that it is essential to seek for a new teaching style, which is teaching through using the video, being one of the modern ways.

However, to make video more effective, it must be available, easy to use, well maintained, adequately funded and experts must be available. It is alarming to note that virtually all lecturers or teacher does not make use of instructional materials to deliver lectures. It is in light of this, that this study investigated the effect of video in teaching.

\subsection{Research Objectives}

The research aims to identify the effect of using video on developing physical fitness of physical education students at the Hashemite University.

\subsection{Research Hypotheses}

1) There are statistically significant differences at the $0.05>\alpha$ level between the pre and post measurement means of the control group.

2) There are statistically significant differences at the $0.05>\alpha$ level between the pre and post measurement means of the experimental group.

3) There are statistically significant differences at the $0.05>\alpha$ level between the post measurement means of the control and experimental groups in all physical fitness aspect.

\section{Method}

\subsection{Research Design}

The researchers employed the two-group design with pre-posttest with a control group. 


\subsection{Population and Sample}

The target population for this study consisted of all students enrolled in physical fitness class at the faculty of physical education during the academic year 2011/2012 ( $N=40$ ). The sample included (20) students chosen intentionally and distributed in to two equal groups, experimental group and control group. Table (1) shows equivalence of the two groups on certain growth rates.

Table 1. Study sample equivalence on certain growth rates (age, height, weight) and physical variables $(\mathrm{N}=10)$

\begin{tabular}{lccccccc}
\hline \multicolumn{1}{c}{ Variables } & \multicolumn{3}{c}{ Control Group } & \multicolumn{2}{c}{ Experimental Group } & \multirow{2}{*}{ T } & \multirow{2}{*}{ P-Value } \\
& M & SD & M & SD & & \\
\hline Age & \multicolumn{2}{c}{ Growth Rates } & & & & \\
Height & 20.54 & 0.59 & 20.22 & 0.65 & 0.53 & 0.814 \\
Weight & 168.24 & 3.65 & 167.65 & 5.32 & 0.61 & 0.673 \\
& 74.22 & 3.94 & 70.30 & 3.25 & 1.28 & 0.185 \\
Vertical Jump from Stability & Physical Variables & & & & \\
Throwing and receiving the ball & 14.98 & 1.99 & 15.31 & 1.86 & 0.56 & 0.580 \\
Trunk Bending Forward from Standing & 13.96 & 2.89 & 13.77 & 13.77 & 0.37 & 0.714 \\
Zigzag Running & 12.23 & 1.99 & 12.88 & 2.35 & 0.88 & 0.386 \\
Throwing a Ball to the farthest Distance & 7.93 & 2.13 & 8.02 & 2.36 & 0.76 & 0.454 \\
25 m Running & 18.66 & 4.36 & 18.52 & 3.98 & 0.18 & 0.858 \\
\hline
\end{tabular}

Table 1. illustrates that the significance level of all the variables is higher than 0.05 , meaning that there is no difference between the two study groups on all variables.

\subsection{Research Tools}

The Researchers used the following equipments to conduct this study: document analysis; appliances and instruments; equipments: (Rest Meter, Medical scale, Measuring tape, Stopwatch, hurdles, balls, and physical tests.

\subsection{Validity and Reliability of Physical Variables Tests \\ - Validity:}

Content validity of physical tests was verified through presenting them to a panel of experts in the field of physical education. They proved to be valid.

\section{- Reliability:}

Reliability was demonstrated using test- retest over a 7-days period. Ten students participated and they were not from the research sample. Table (2) shows the correlation between the first and second application, and subsequently, the reliability of the physical measurements.

Table 2. Mean, standard deviation and correlation coefficient between the first and second applications of the physical variables, $\mathrm{N}=10$

\begin{tabular}{lccccc}
\hline Variables & \multicolumn{3}{c}{ First Application } & \multicolumn{3}{c}{ Second Application } \\
& $\mathrm{M}$ & $\mathrm{SD}$ & $\mathrm{M}$ & $\mathrm{SD}$ & $\mathrm{R}$ \\
\hline Physical Variables & & & & & \\
Vertical Jump from Stability & 8.23 & 0.22 & 8.15 & 0.65 & 0.86 \\
Throwing and receiving the ball & 18.14 & 2.95 & 18.74 & 2.36 & 0.84 \\
Trunk Bending Forward from Standing & 14.92 & 1.87 & 14.49 & 1.65 & 0.90 \\
Zigzag Running & 15.99 & 1.45 & 16.11 & 1.36 & 0.91 \\
Throwing a Ball to the farthest Distance & 13.58 & 4.65 & 14.63 & 1.54 & 0.87 \\
25 m Running & 12.65 & 4.32 & 12.36 & 3.60 & 0.85 \\
\hline
\end{tabular}


Table 2. shows that the reliability degrees of the physical variables ranged between 0.84 and 0.91 , indicating that there is a correlation between the first and second applications of the physical variables. This further indicates the reliability of all physical tests, as these grades are considered sufficient to carry out this research.

\subsection{Application of the Experiment}

- Pre-Measurements

The researchers carried out the pre-measurements for each of the physical tests during the period from Sunday, 27 February and Wednesday 27 March 2012. See table 1.

\section{- Basic Experiment}

The basic experiment had been applied as per the time schedule of the prescribed module of the physical fitness Course in the Faculty of physical education and Sport Sciences at the Hashemite University over 8 weeks. Two classes per week for the same skill were conducted on Monday and Wednesday, bringing the total to 16 classes. The class time was 50 minutes. The control group was taught by the traditional method (traditional teaching units); the experimental group was taught using the video method. The introductory and final sections were delivered in compliance with the prescribed curricula on both groups.

\section{- Post-Measurements}

The researchers carried out the post measurements for the physical tests, during the period from Sunday 12 June 2011 to Wednesday 15 June 2011.

\subsection{Statistical Analysis}

Data were analyzed using the statistical package of the social sciences (SPSS). Means, standard deviations and T-Test were used to answer study questions.

\section{Results}

First: showing the results concerning the first hypothesis stating: "There are statistically significant differences at the $0.05>\alpha$ level between the pre and post measurement means of the control group. The researches obtained the means, standard deviations and calculated t-test between the pre and post measurement of the control group. Table (3) illustrates the results.

Table 3. Difference Significance between the pre and post measurement on the physical variables of the control group. $\mathrm{N}=10$

\begin{tabular}{lllllll}
\hline \multirow{2}{*}{ Tests } & \multicolumn{2}{c}{ Pre-Measurement } & \multicolumn{2}{c}{ Post-Measurement } & T & P - Value \\
& Mean & SD & Mean & SD & & \\
\hline Vertical Jump from Stability & 14.98 & 1.99 & 15.87 & 2.30 & 1.15 & 0.467 \\
Throwing and receiving the ball & 13.96 & 2.89 & 15.56 & 2.14 & 0.75 & 0.476 \\
Trunk Bending Forward from Standing & 12.23 & 1.99 & 13.22 & 1.67 & 0.85 & 0.737 \\
Zigzag Running & 7.93 & 2.13 & 9.02 & 1.88 & 0.35 & 0.267 \\
Throwing a Ball to the farthest Distance & 18.66 & 4.36 & 21.37 & 4.01 & 0.37 & 0.407 \\
25 m Running & 8.22 & 0.21 & 10.11 & 0.66 & 0.19 & 0.195 \\
\hline
\end{tabular}

Table (3) indicates that there are no statistically significant differences at the $0.05 \geq \alpha$ between the pre and post measurement means of the control group.

Second: showing the results concerning the second hypothesis stating " There are statistically significant differences at the $0.05>\alpha$ level between the pre and post measurement means of the experimental group. The researchers obtained the means, standard deviations and calculated T-test between the pre and post measurements of the experimental group. Table (4) illustrates this. 
Table 4. Difference significance between the pre and post measurement on the physical variables of the experimental group. $\mathrm{N}=10$

\begin{tabular}{lllllll}
\hline \multirow{2}{*}{ Tests } & \multicolumn{2}{c}{ Pre-Measurement } & \multicolumn{2}{c}{ Post- Measurement } & T & P-Value \\
& Mean & SD & Mean & SD & & \\
\hline Vertical Jump from Stability & 15.31 & 1.86 & 19.14 & 0.91 & 4.34 & 0.000 \\
Throwing and receiving the ball & 13.77 & 13.77 & 17.50 & 1.20 & 3.16 & 0.005 \\
Trunk Bending Forward from Standing & 12.88 & 2.35 & 15.01 & 1.16 & 3.24 & 0.004 \\
Zigzag Running & 8.02 & 2.36 & 11.70 & 1.35 & 3.17 & 0.007 \\
Throwing a Ball to the farthest Distance & 18.52 & 3.98 & 24.09 & 1.28 & 3.36 & 0.003 \\
25 m Running & 8.01 & 0.66 & 12.44 & 1.38 & 2.55 & 0.021 \\
\hline
\end{tabular}

Table (4) indicates that there are statistically significant differences at the $0.05 \geq \alpha$ between the pre and post measurements means of the experimental group in favor of the post measurement.

Three: showing the results of the third hypothesis stating". There are statistically significant differences at the $0.05>\alpha$ level between the post measurement means of the control and experimental groups in all physical fitness aspects. The researchers obtained the means, standard deviations and calculated T-test between post measurements of the control and experimental groups. Table (5) illustrates this.

Table 5. Different Significance the post measurements between the control and experimental groups on the physical variables. $\mathrm{N}=20$

\begin{tabular}{|c|c|c|c|c|c|c|}
\hline \multirow[t]{2}{*}{ Tests } & \multicolumn{2}{|c|}{ Control Group } & \multicolumn{2}{|c|}{ Experimental group } & \multirow[t]{2}{*}{$\mathrm{T}$} & \multirow[t]{2}{*}{$\mathrm{P}$ - Value } \\
\hline & Mean & SD & Mean & $\mathrm{SD}$ & & \\
\hline Vertical Jump from Stability & 15.87 & 2.30 & 19.14 & 0.91 & 3.59 & 0.000 \\
\hline Throwing and receiving the ball & 15.56 & 2.14 & 17.50 & 1.20 & 2.47 & 0.001 \\
\hline Trunk Bending Forward from Standing & 13.22 & 1.67 & 15.01 & 1.16 & 3.26 & 0.000 \\
\hline Zigzag Running & 9.02 & 1.88 & 11.70 & 1.35 & 17.15 & 0.000 \\
\hline Throwing a Ball to the farthest Distance & 21.37 & 4.01 & 24.09 & 1.28 & 13.98 & 0.000 \\
\hline 25 m Running & 10.11 & 0.66 & 12.44 & 1.38 & 10.11 & 0.001 \\
\hline
\end{tabular}

Table (5) indicates that there are statistically significant differences at the $0.05 \geq \alpha$ in post measurements of the control and experimental groups in physical fitness in favor of the experimental groups.

\section{Discussion}

The first hypothesis stating that there are statistically significant differences on the physical variables between the pre and post measurement of the control group, which used the traditional teaching method. The researchers ascribe the emergence of this result to the inability of the traditional method to fulfill the needs of the students, and absence of motivation to attract students because of using the traditional teaching method. Oudat (2010) and Al-Shahhat (2002) stated that the traditional method does not lead to high results, or a noticeable improvement with the students, supported this finding.

Accordingly, the researchers see that it is essential to diversify the methods and ways that fit their abilities, tendencies and needs. This is agree with the studies of Lin (2005) and Osthuzen and Griesel (1992), who said that the traditional method does not realize any major and effective development in the physical and skill variables as compared with the modern teaching styles.

The second hypothesis stating that the use of a new method in teaching had realized better results than the traditional method. This study is in harmony with the study conducted by Hussein (2006) underlining that there must be new and diversified methods and styles in teaching, as they have good effects on the students' performance and in improving their levels.

This agree with the study of Fatunmbi (2005) that there is improvement in the teaching with video. According to 
him, video can be used to provide real experiences in almost all field of learning. It can be made to repeat information and demonstration, as many times as possible, thereby, learning is made easier, realistic and concrete for learners. It allows for self-instruction. It provide a cheap and fast way of disseminating educational information and practical skills.

The researchers attribute this result to the nature of the video style, which is characterized by giving weight to the individual differences among the learners; and that the learner himself selects the starting level proportional to his abilities, tendencies and readiness. The student himself evaluates his performance, corrects his mistakes through the video. This finding was supported by Izz-Eddin (2005) that teaching using the video style allows every learner selects the starting level relevant to his abilities through the educational steps with graded levels of difficulty; so that the learner will select whatever suiting his abilities, to reach the final requirement. Thereby, this style takes into account the individual differences, which will lead to better results in the teaching process.

The third hypothesis stating means that the use of video had a positive effect on improving physical fitness, through availing the opportunity for positive and effective participation, as well as the ongoing feedback due to the observation of the proper skill performance method as long as possible. This is quite in harmony with the implication of the studies of Oudat (2012) and Hussein (2006), stating that the use of the video method is much better than the traditional method. The researchers think that the traditional teaching method does not lead to high results or a noticeable improvement with the students, and irrelevance of this method to their tendencies. Therefore, it is necessary to employ methods and styles that fit their abilities.

The researchers ascribe this result to using the video in teaching has a clear positive effect on the improvement of physical fitness. That is because this style contributes in activation of the teaching process and makes the learning process more positive and effective, which, by turn, contributes in raising the abilities of physical fitness O'loughlin .et .al (2013) and Beshnizen and Van Puthen (2000) supported this finding that video can help the teacher to work more closely with the learner and reduce the need for repeated explanation. It has the capacity to motivate learners and difficult skills are better viewed especially with the slow motion.

This hypothesis agrees with the finding of Al-Sayyad (2005) which indicated that there were improvements in the examinations results as a result of the use of new teaching styles, which have more clear effects on the students than the use of the traditional method employed by teachers, a method that surpasses the students needs, which require plans and guidance programs to overcome the difficulties and problems facing them. The results of this current study also agrees with the study made by Banville and Polifko (2009) and Fu and Sheng (2009) stating that the use of the different and various teaching styles, which work on adjusting the educational situation, and create an atmosphere of change on the regular track of the traditional method. This is quite clear from the results emerged from his study and was in agreement with the results of this study.

Based on the results of the hypotheses, the researchers see that the use of the video teaching style with the students will lead to a noticeable improvement in their performance, and help them face the problems that come out in their way and overcome these problems. It also helps physical education teachers to use modern and various teaching styles that are proportional to their abilities, and fits their tendencies and needs. Furthermore, it helps teachers discover the problems and difficulties that obstruct the teaching process and how to tackle them.

\section{Conclusions}

The researchers concluded that the use of video showed a better improvement rate than the traditional method in developing physical fitness for physical education and sport sciences faculty students at the Hashemite University.

\section{Recommendations}

The researchers recommended the following:

1) It is necessary to use video in the physical fitness courses.

2) Teachers are recommended to use methods and styles that fit their students and diversify the application of the audiovisual stimuli.

3) As for the area of research and studies, the researchers recommend to conduct a similar study with different populations and to include more variables.

\section{References}

Alaku, P. O. (1998). Instructional strategies and audio-visual aids for teachers' effectiveness. Bichi Journal of Education, 2(1), 114-117. 
Al-Labani, S. T. (1991). Impact of the Problem-Solving Method on Attaining the Goals of Certain Tennis Skills. Unpublished Doctoral Dissertation, Alexandria University, Egypt.

Al-Sayyad, H. A. (2005). Effect of the two methods of harmony and construction and additional assignments on certain physical and skill variables in the physical education lesson. Unpublished Master Thesis, Helwan University, Egypt.

Al-Shahhat, M. M. (2002). Effect of the use of certain teaching methods on learning some basic skills in hockey sport for the students of the physical education college, Al-Mansoura University. The Scientific Journal Sports Sciences and Arts, Helwan University, 16(2).

Ayinde, A. T. (1999). Resources for Effective Teaching and Learning of Agricultural Science. Bichi Journal of Education and Planning, 1(1), 6-8.

Banville, D., \& Polifko, M. (2009). Using Digital Video Recorders in Physical Education. Journal of Physical Education, Recreation \& Dance, 80(1), 17-21. http://dx.doi.org/10.1080/07303084.2009.10598262

Beshnizen, M., \& Puthen, V. (2000). The use of videotape broadcast and interactive teaching. British Journal of Edu Tech, 21(2), 40-44.

Fatunmbi, O. O. (2005). Effect of video tape presentation on senior secondary school students attitudes towards physical education. Journal of Teacher Education, 8(1), 56-64.

Fu, D. X., \& Sheng, Z. C. (2009). Research on Stratification Teaching Method in Vocational College Basketball Teaching. Bulletin of Sport Science \& Technology.

Hussein, M. K. (2006). Effectiveness of some methods used to adjust the educational situation of the learner's characteristics. Unpublished doctoral dissertation, Helwan University, Egypt.

Izz-Eddin, A. A. (2005). Teaching in physical education: Methods, styles, strategies. Egypt: Shajart Al-Dorr Bookshop.

Lin, C. C. (2005). The comparison of the teaching effects among Moston teaching spectrum applies to junior high school basketball camp. National Taiwan College of Physical Education.

Mohammad, T. M. (2006). Effect of the use of the multi-shaped motor assignments on learning certain attacking skills in handball sport for the faculty of physical education students: A comparative study. Unpublished Master thesis, Al-Mansoura University, Egypt.

Moston, M. (1981). Teaching physical education (2nd ed.). Columbus, London: Charles E. Merrill Publishing Co.

O'loughlin, J., Chróinín, D. N., \& O’Grady, D. (2013). Digital Video: The impact on children's learning experiences in Primary Physical Education. European Physical Education Review, 19(2), 165-182. http://dx.doi.org/10.1177/1356336X13486050

Osthuzen, N., \& Griesel, J. (1992). The effect of the command, reciprocal and inclusion teaching styles on realization of objective in physical education for high school boys. Journal for Research in Sport Physical Education and Recreation, 15(2), 27-32.

Oudat, M. A. (2006). Effective Physical Educator's Use of Remedial Teaching Style to Those Motor Learning Disabilities in Physical Education Lesson. Unpublished Doctoral Dissertation, Helwan University, Egypt.

Oudat, M. A. (2010). The Effectiveness of using the cooperative and interchange learning style in motor achievement on some table tennis for hyper basic stage student. Physical Education Sciences and Arts Journal, Assiut University, 31(1), 1-27.

Oudat, M. A. (2012). A Comparative study of the impact of some teaching styles applied on certain physical and skill variables in basketball for the Faculty of Physical Education and Sport Science Students at the Hashemite University. International Journal of Academic Research Part B, 4(6), 83-89. http://dx.doi.org/10.7813/2075-4124.2012/4-6/B.14

\section{Copyrights}

Copyright for this article is retained by the author(s), with first publication rights granted to the journal.

This is an open-access article distributed under the terms and conditions of the Creative Commons Attribution license (http://creativecommons.org/licenses/by/3.0/). 